Plant Tissue Cult. \& Biotech. 23(1): 115-120, 2013 (June)

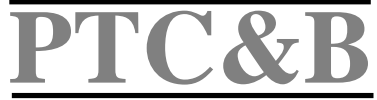

\title{
Evidence of Floral Reversion during In vitro Shoot Regeneration from Young Inflorescence of the Medicinal Geophyte Gloriosa superba L.
}

\author{
Supriyo Sen ${ }^{1}$, V. Krishnasamy, S. Krishnaveni, C. Vijayalakshmi, \\ K. Rajamani ${ }^{2}$ and R. Gnanam \\ Centre for Plant Molecular Biology, Tamil Nadu Agricultural University, \\ Coimbatore- 641003, India
}

Key words: Gloriosa superba, Floral reversion, Young/immature inflorescence, Geophyte, Direct organogenesis, Micropropagation

Flower and inflorescence reversion is an ongoing process in floral development that is modulated in response to inherent plant signals or environmental cues. Under in vitro condition, use of appropriate growth medium and environment has also been found to trigger similar phase reversion in some plant species. In Gloriosa superba this is the first report of reversion from immature inflorescence explants where multiple shoots (up to 11.2 shoots/explant) in MS containing BAP $(5.0 \mathrm{mg} / \mathrm{l})$ and NAA $(2.0 \mathrm{mg} / \mathrm{l})$ was achieved. The shoots were successfully rooted and hardened under greenhouse conditions before establishment in field within 100 - 110 days. This provides an alternative platform for high frequency of regeneration for multiplication of this valuable medicinal species and other such economically important geophytes.

Micropropagation requires the induction of multiple vegetative buds usually from pre-existing vegetative meristems. Meristem identity is an important aspect of plant development which is stable unless during events such as switch over from vegetative to reproductive growth or less frequently in reversion from floral to vegetative growth that has been observed in response to inherent plant signals or environmental cues (Huala and Sussex 1993). This fact of reversion can be utilised effectively as an alternative option for micropropagation of responsive species. Gloriosa superba (Colchicaceae) is an important medicinal geophyte cultivated commercially in several parts of peninsular India for use in extraction of the medicinal biomolecules such as colchicine, colchicoside and also in several

${ }^{1}$ Present address: Division of Life Sciences, Institute of Advanced Study in Science and Technology, Guwahati -35, Assam, India. ${ }^{2}$ Horticultural College and Research Institute, Tamil Nadu Agricultural University, Coimbatore-641003, India. 
other traditional medicinal practices. Geophytes mostly have a low natural propagation rate and many species are propagated in vitro (Kim et al. 1997). Apical and axillary buds are most commonly used as explants for the propagation of geophytes in vitro. However, the regeneration potential of these organs is species and genotype dependent. The use of underground storage organs as a source of explants is associated with the possibility of encountering heavy contamination. The inflorescence stalk is regarded as an excellent source of contamination free explants that can become a viable alternative. In geophytes such as Alstroemeria, Amaryllis, Gladiolus, Ornithogalum, Narcissus, Hyacinthus, a high frequency of shoot bud formation has already been reported using inflorescence derived explants (Ziv et al. 1970, Ziv et al. 1973, Ziv 1979, De Bruyn et al. 1992). In vitro regeneration of Gloriosa superba has been reported by axillary and/or adventitious shoot formation from tuber sprouts (Finnie and Van Staden 1989, Custers and Bergervoet 1994, Ziv and Lilien-Kipnis 2000), shoot tips and nodal segments (Sivakumar and Krishnamurthy 2000 and 2004, Hassan and Roy 2005) with variable frequencies of shoot multiplication. However, commercial micropropagation for this important medicinal plant is still not available for this valuable species. Lower natural rates of propagation coupled with a large scale collection of plant parts from the forests has created undue pressure on the sustainability of their wild populations which further calls for an urgent and viable alternative for large scale multiplication. To the best of present authors' knowledge there is no report of floral reversion from young inflorescence of $G$. superba. The present study reports the evidence of reversion of young inflorescence tissue and a high frequency of regeneration of shoots following induction of multiple shoot buds that can be used as an alternative approach for micropropagation of this valuable medicinal species and other economically important geophytes.

Inflorescences of G. superba at the early stages of growth were obtained from the experimental plots of the Department of Medicinal and Aromatic Crops, Tamil Nadu Agricultural University at Coimbatore and at Odanchhatram (Dindigul district) in Tamil Nadu. After removal of mature leaves and florets the upper tender portion of the inflorescence stalk was subjected to surface sterilization with $\mathrm{HgCl}_{2}(1.0 \mathrm{~min})$ followed by ethanol $(30 \mathrm{sec})$. Portion of stalk retaining the 1st, 2 nd and 3rd florets were then isolated under $4 \mathrm{X}$ magnification of a compound microscope which served as the explants (Fig. 1a). These isolated explants were inoculated into modified MS to study the effect of addition of different types and concentrations of cytokinins alone or in combination with an auxin (NAA). The cultures were maintained at $25 \pm 2^{\circ} \mathrm{C}$ at a relative humidity of 60 - 70 per cent and at a light intensity of 3000 lux at a photoperiod of 16/8 hrs in light 
and dark. Responding explants were sub-cultured every three weeks into the same medium for further development. After 60 days in culture shoots were separated from clumps and inoculated into rooting media. Rooted plantlets were hardened and established in suitable growth medium under greenhouse environment. The experiments were replicated three times and the data were analyzed statistically by adopting LSD analysis after ANOVA to group the treatment means.
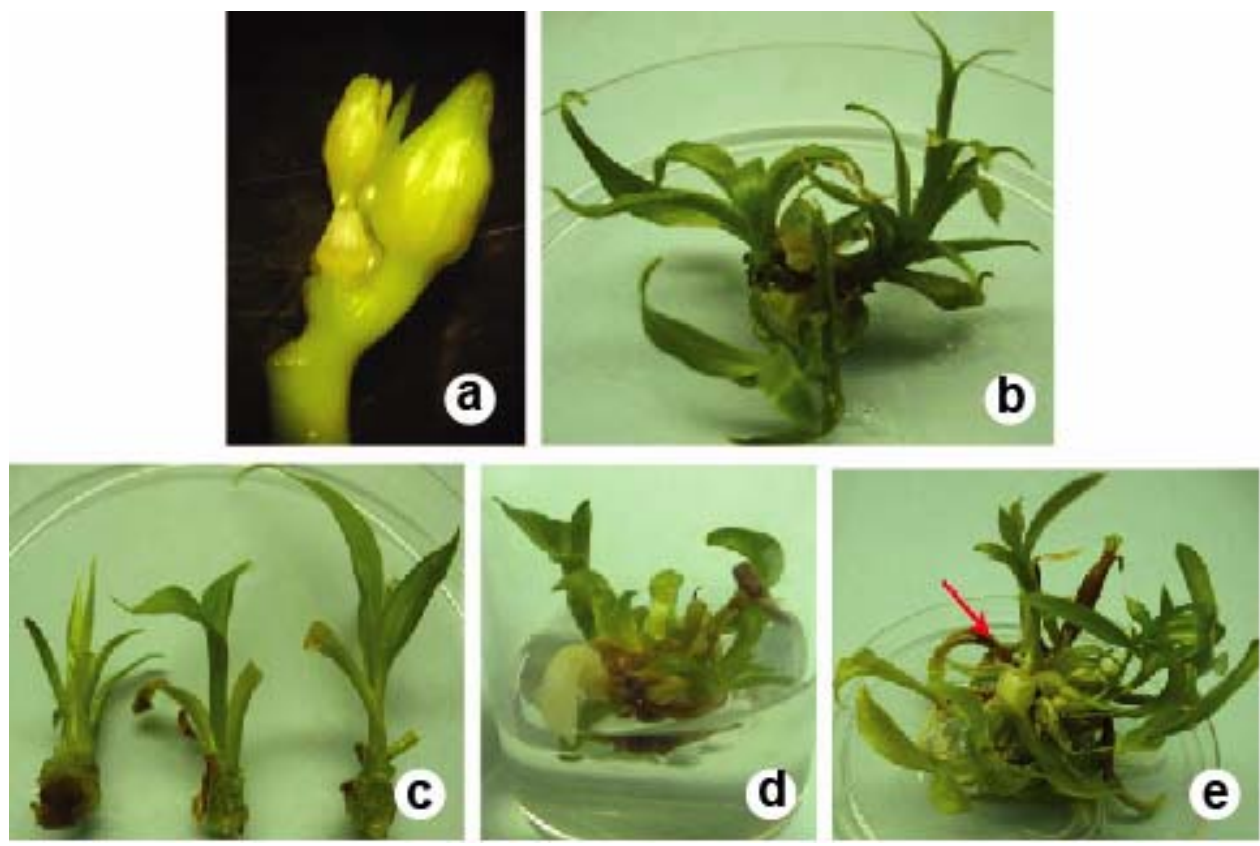

Fig. 1. Direct regeneration by floral reversion from young inflorescence of Gloriosa superba. a. Terminal three floret explants derived from young infloresence (seen under $4 \mathrm{X}$ magnification). $\mathrm{b}$. Explant with stalk showing floral reversion (into leafy structures) after 15 days of culture in MS containing $5.0 \mathrm{mg} / \mathrm{l} \mathrm{BAP}$ and $2.0 \mathrm{mg} / \mathrm{l} \mathrm{NAA}$. c. The vegetative structures formed after reversion are separated into individual shootlets. $d$, e. Induction of multiple vegetative shoot buds from the reverted vegetative stalks after 30 days of culture in the same medium and their subsequent development into shootlets (arrow) suitable for separation for rooting and establishment as plantlets.

Reversion is considered to result from the lack of determination (commitment) in a meristem. A way to study this is to grow the meristem away from the sources of plant signals that can induce inflorescence or floral fate. In vitro culture offers this unique opportunity as it allows complete isolation of the tissue as well as some control on growth conditions for example, number of leaves, hormonal type/level, and nutrient sources (McDaniel et al. 1992, Donnison and Francis 1994). Only explants from young inflorescence bearing the 
terminal three floral buds that were grown in vitro in presence of different combinations and compositions of hormones responded to reversion and development of multiple shoots (Fig. 1b-e).

Morphological changes were observed in the explants from 8 - 10th day when the florets changed in form and morphed into leafy structures attached to pre-existing pedunclular and pedicellar stalks. This is indicative of flower reversion (and not inflorescence reversion) where the form of the flower is altered and floral tissues may be replaced with vegetative tissue such as leaves. The shoots when prominent in cultures were separated and inoculated into the same medium for further growth and morphogenesis. Multiple shoot buds were
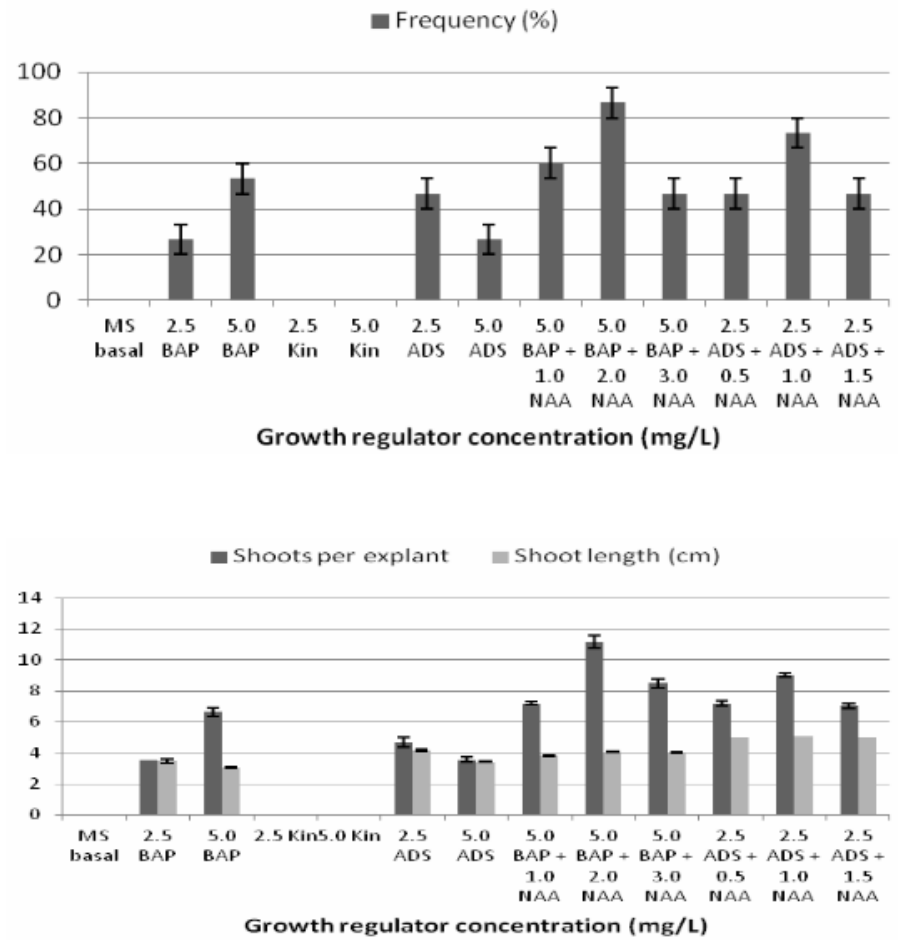

Fig. 2. Effect of growth regulators on in vitro floral reversion and direct shoot regeneration from young inflorescence tissues of Gloriosa superba. a. Frequency of explants undergoing floral reversion leading to direct shoot regeneration after 30 days in culture. b. Number of shoots formed per explant and mean shoot length attained by the regenerated shoots after 60 days in culture.

initiated from the growing shoots till 30 - 45 days in culture. The findings are graphically summarised in Fig. 2. MS supplemented with $5.0 \mathrm{mg} / \mathrm{l} \mathrm{BAP}$ and 2.0 $\mathrm{mg} / \mathrm{l} \mathrm{NAA}$ and $2.5 \mathrm{mg} / \mathrm{l}$ ADS with $1.0 \mathrm{mg} / \mathrm{l}$ NAA elicited the highest frequency of shoot induction at 86.7 and $73.33 \%$, respectively (Fig. 2a). The possible route to 
the regeneration of shoots initially might be from the reversion of young florets towards conversion into vegetative shoots followed later by the activation of the meristematic buds located in the peduncle-pedicel junction in response to elevated levels of cytokinin exposure to the tissues to yield multiple shoot buds. In Allium ampelospasum, shoot induction from peduncle-pedicel junction has been reported using 5.4 $\mu \mathrm{M}$ NAA and $25 \mu \mathrm{M}$ BAP (Ziv and Lilien-Kipnis 2000). In the present study combination of NAA with BAP, ADS was consistently found to be stimulatory. However, BAP and ADS alone could elicit response only in 45-50 per cent explants and those in Kn containing medium merely swelled into hard clump like structures and remained quiescent which later became necrotic. Highest number of shoots per explant was seen in media containing BAP (5.0 $\mathrm{mg} / \mathrm{l})$ and NAA $(2.0 \mathrm{mg} / \mathrm{l})$ where explants regenerated up to 11.2 shoots per explant on average. Shoots growing in the multiple shoot clumps attained length of $3.0-5.0 \mathrm{~cm}$ over 60 days in different media compositions. ADS in all combinations with NAA had a significant stimulatory effect on shoot length where shoots grew up to a mean height of $5.0-5.1 \mathrm{~cm}$ (Fig. 2b). Shoots developed were transferred directly into rooting medium since they were sufficiently long and erect. According to hormonal control of organogenesis, a high cytokinin to auxin ratio favours differentiation (Skoog and Millar 1957). Also one of the possible roles of auxins is to nullify the effect of high cytokinin concentration on shoot elongation and to restore normal shoot growth. In this case, therefore, 2.0 $\mathrm{mg} / \mathrm{l}$ NAA helped to allow normal shoot growth together with multiple shoot growth as a result of the effect of BAP. Half MS $+0.5 \mathrm{mg} / \mathrm{l}$ NAA was used for rooting the plants before transferring into hardening substrate comprising of red soil, vermicompost and sand mixed in equal proportion. Some shoots showed a prominent bulge at the basal portion of the shoot which developed into in vitro microtubers that could be harvested separately. The plants rooted successfully at a frequency of 80 - 85 per cent within a period of 30 days and were established under field conditions after a period of 14 days of acclimatisation.

Flower and inflorescence reversion involve a return from floral development back to vegetative stage, thus rendering flowering phase in an ongoing growth pattern rather than a terminal act of the meristem (Tooke et al. 2005). This phenomenon can be modulated under in vitro condition by the use of appropriate growth medium and environment. In the present study the choice of explants and growth regulators accorded the maximum influence over the induction of reversion and possible stimulation of meristems of the pedunclepedicel junction to regenerate shoots in high frequency. This can be adopted as a viable alternative to large scale multiplication of G. superba and other such valuable geophytic species. 


\section{Acknowledgement}

DBT doctoral fellowship was awarded first author (SS) is gratefully acknowledged.

\section{References}

Custers JB and Bergervoet JHW (1994) Micropropagation of Gloriosa: Towards a practical protocol. Scientia Horti. 7: 323-334.

De Bruyn MH, Ferreira DI, Slabbert MM and Pretorius J (1992) In vitro propagation of Amaryllis belladonna. Plant Cell Tiss. Org. Cult. 31: 179-184.

Donnison IS and Francis D (1994) Experimental control of floral reversion in isolated shoot apices of the long-day plant Silene coeli-rosa. Physiol. Plant. 92: 329-335.

Finnie JF and Van Staden J (1989) In vitro production of Sandersonia and Gloriosa. Plant Cell Tiss. Org. Cult. 19: 151-158.

Hassan AKMS and Roy SK (2005) Micropropagation of Gloriosa superba L. through high frequency shoot proliferation. Plant Tiss. Cult. 15(1): 67-74.

Huala E. and Sussex IM (1993) Determination and cell interactions in reproductive meristems. The Plant Cell 5: 1157-1165.

Kim KW and De Hertogh AA (1997) Tissue culture of ornamental flowering geophytes. Hortic. Rev. 18: 87-169.

McDaniel CN, Singer SR and Smith SME (1992) Developmental states associated with the floral transition. Developmental Biol. 153: 59-69.

Sivakumar G and Krishnamurthy KV (2004) In vitro organogenetic responses of Gloriosa superba. Russian J. Plant Physiol. 51(5): 713-321.

Sivakumar G and Krishnamurthy KV (2000) Micropropagation of Gloriosa superba L - An endangered species of Asia and Africa. Curr. Sci. 78(1): 31-32.

Skoog F and Millar CO (1957) Chemical regulation of growth and organ formation in plant tissue culture in vitro. In: The biological action of growth substances. (H.K. Porter, Ed.). Academic Press, NY, US. pp. 118-131.

Tooke F, Ordidge M, Chiurugwi T and Battey N (2005) Mechanisms and function of flower and inflorescence reversion. J. Exp. Bot. 56(420): 2587-2599.

Ziv M and Lilien-Kipnis H (2000) Bud regeneration from inflorescence explants for rapid propagation of geophytes in vitro. Plant Cell Rep. 19: 845-850.

Ziv M, Halevy AH and Shilo R (1970) Organs and plantlets regeneration of Gladiolus through tissue culture. Ann. Bot. 34: 671-676.

Ziv M, Kanterovitz R and Halevy AH (1973) Vegetative propagation of Alstromeria in vitro. Sci. Hortic. 1: 271-277.

Ziv M (1979) Transplanting in vitro propagated Gladiolus plants. Sci. Hortic. 11: 257-260. 